Mehmet Akif Ersoy Üniversitesi Fen Bilimleri Enstitüsü Dergisi 10(2): 150-158 (2019)

The Journal of Graduate School of Natural and Applied Sciences of Mehmet Akif Ersoy University 10(2): 150-158 (2019)

Araştırma Makalesi / Research Paper

\title{
Çanakkale Kentsel Yapısına Eleştirel Bir Yaklaşım: Butik Kent
}

\author{
Yavuz ALKAN \\ Çanakkale Onsekiz Mart Üniversitesi, Lapseki Meslek Yüksekokulu, Çanakkale \\ Geliş Tarihi (Received): 12.08.2019, Kabul Tarihi (Accepted): 16.10.2019 \\ $\square$ Sorumlu Yazar (Corresponding author): yalkan58@comu.edu.tr \\ (C) +902865226104 且 +902865226101
}

\begin{abstract}
ÖZ
Butik kent, dünyada pek çok örneği olan, bilindik kent görünümünden uzak, kentin tamamına bisikletli ve yaya ulaşım mesafesinde olan, yer yer dar sokak tekstürüne sahip, kent insanının doğal, tarihi, kültürel, dini, sosyal, ekonomik ve rekreasyonel faaliyetlerini karmaşık kent koşullarından uzak daha ergonomik olarak sergiledikleri, pratik kentlerdir. Fransızca kökenli bir kelime olan "Butik" kelimesi, ülkemizde geçmişten gelen dükkan, mağaza anlamlarında kullanıIırken, sonraları/günümüzde anlam genişlemesi ile birlikte tasarımı farklı, özgün, özenle yapılmış gibi anlamlarla da kullanılmaktadır. Bu açıdan, kullanıma bağlı olarak farkı tasarımlardan kaynaklı Çanakkale kent merkezinde trafiğe kapalı cadde ve sokakların varlığı söz konusudur. Kent dokusundaki bu yönelimde ve özellikle, kentin yapısal planlamalarıyla belirginleşen Butik Kent olma noktasında, konumu, yerleşim planı ve kompakt kent dokusunda olmasının yanı sıra Sivil Toplum Kuruluşları, kamu ve yerel yöneticilerden oluşan çoklu aktörlerin etkisi de tartışılmazdır. Ancak bu dinamizmin tersine, mevcut yapısı itibariyle kentin merkezi konumunda bulunan iskele donatısından kaynaklı araç trafiğinin kentin içlerine kadar yönelmesi, tüm yıl olduğu gibi, özellikle turizm mevsimine bağlı olarak da bunun artış göstermesi, Çanakkale'yi pratik kent algısından uzaklaştırmaktadır. Mevcut durumun görsellerle ve literatür çalışmalarıyla desteklendiği bu çalışmada iskele yapısı ve buna bağlı araç trafiğinden kaynaklı olumsuzlukların giderilmesi yönünde atılacak adımlar ile peyzaj planlamasına katkı noktasında sergilenecek rasyonel ve sürdürülebilir yaklaşımların bu doğrultuda alınacak kararlarla Çanakkale'nin butik kent yapısına büyük katkı sağlayacağı planlanmaktadır.
\end{abstract}

Anahtar Kelimeler: Çanakkale, kentsel yapı, peyzaj planlama, rasyonel kullanım, butik kent

\section{A Critical Approach to Çanakkale Urban Structure: Boutique Town}

\section{ABSTRACT}

Boutique towns, of which there are many examples globally, are practical towns with more ergonomic features for the natural, historical, cultural, religious, social, economic and recreational activities of townspeople removed from the conditions in complicated towns. The towns appear different to most towns, with the whole town located within bicycling or walking distance and occasional narrow street textures. The word "boutique" with French origin was used in the sense of shop or store in Turkey in the past, before later gaining the expanded meaning of different, unique or careful design. From this aspect, the presence of pedestrian streets and avenues in Çanakkale town center can be mentioned due to different designs linked to use. These orientations and features of the town texture are undoubtedly the effect of structural planning of the town at the point of clearly being a boutique town, and also location, settlement plan and compact town texture, in addition to multiple actors comprising non-governmental organizations, public and local administrators. However, contrary to this dynamism, based on the current structure the presence of the pier found in a central location in the town distances Çanakkale from the practical town perception due to directing of vehicular traffic into the town all year round, with increases especially linked to the tourism season. In this study, supported by visual images of the current status and a literature review, the plan is to contribute greatly to the boutique town structure of Çanakkale with steps made to remove the negativities caused by the pier structure and linked 
vehicular traffic and decisions taken in line with rational and sustainable approaches at the point of landscape planning.

Keywords: Çanakkale, urban structure, landscape planning, rational use, boutique town

\section{GíRiş}

Tarihte kent yapısının oluşması insanoğlunun yerleşik hayata geçişiyle başlamıştır (Pustu, 2006). İnsan yaşamında kentler çok hızlı biçimde değişme ve yeni rol üstlenme potansiyeline sahip yerleşimlerdir (Eroğlu ve Yalçın, 2014). Günümüzde kent kavramının iki önemli boyutuyla öne çıktığını söyleyebiliriz. İlki Siyasal boyutu olup idari ve demografik yapıyla belirginlik gösterir (Weber, 2003). İkincisi de, sosyal ve kültürel boyutudur (Wirth, 2002). Sosyal ilişkilerde kültür alışverişi bu kapsamda önem arz etmektedir (Yazar, 2015). Kültür etkileşimiyle de nesiller intiyaçlarına uygun olarak biçimlenmekte ve sosyal bütünlükte yerini almaktadırlar (Tatıdil, 1992). Tüm bu dinamiklerin zemin bulduğu kentlerde fiziki, sosyal, ekonomik, dini ve iklimsel faktörler gibi geniş açılı yaşam şartları kentleşmeyi de beraberinde getirmektedir (Kurt, 2018). Kentleşmenin toplum için sağlıklı bir işleyiş açısından bakıldığında iletişim noktasında önemli bir yanı olduğu ve bu açıdan planlama ağırlıklı gelişim göstermesi öncelikli olmaktadır. Dolayısıyla bu sezgiyle beliren kent yapısında yani sosyal ilişkileri buluşturma noktasında planlanmış bir kent yapısı insanları daha rasyonel bir kent kültürü ortamında bulundurmayı hedef alması noktasında önemlidir. Bunun için de kişileri bir araya getiren dış mekan tasarımları önem arz etmektedir. İletişim ağırlıklı sosyal ilişkilerin artması toplumsal refah artışına da yol açabilecektir (Cereci, 2010). Zaman içerisinde değişim ve gelişime bağlı olarak farklı tasarımlarla belirginlik kazanan butik kentler, bir bölgedeki diğer kentlerden çeşitli yönlerle ayrılan niteliklere sahiptirler. Gerek mimari yapısı, sosyo-kültürel yapısı gerekse yaşam şekli ile tasarımı farklı, özgün, özenle yapılmış planlamalarıyla oluşmuş kent yapısındadırlar. Ayrıca, sosyal yaşam tarzı olarak bireylerin iş-ev-sosyal faaliyetlerle ve özellikle kendisi ve yakınları için fazlaca zaman ayırabildiği, araç ve trafikten azami yoksun olan ve kent içinde her yere yürüme mesafesinde olan kent biçimleri olarak öne çıkmaktadırlar. İklimsel faktörlerin de sağlıklı kent yapılarında önemli bir boyut oluşturduğundan bahsedilebilir. Orman, göl, akarsu ve kıyı alanlarının kentsel alanda iklim değişikliğinde önemli bir yeri vardır. Bunun tersi de mümkün olup, trafik, sanayi, sera gazları gibi karbon emisyonlarının termal konforu etkilediği ve iklim değişikliği sorununa yol açtığından da bahsedilebilir. İklim faktörünün insan yaşamında önemli bir yeri vardır. Bu durum hızlı büyüyen kentlerde daha ön plandadır. Kent dokusunda rasyonel bir planlama ve yönetim anlayışı olmadan bireyin yaşam kalitesinde ilerleme olabileceği intimali çok düşüktür. Dolayısıyla kentte sürdürülebilir planlama sağlanarak kentlerin çevresel sürdürülebilirliği sağlanabilir, kentetlerdeki ısı adalarında iyi bir fiziksel planlama ile iklim değerlerinin aralığı düzenlenebilir. Günümüze yakın çalışmalarda insanın yaşam kalitesini artıran biyo-iklimsel konfor bölgesinin olduğunu göstermektedir. Kentlerde kentsel ısı adalarını en aza indirgemek için rekreasyon alanı ve arazinin erişilebilirliği planlanmalıdır. Son yıllarda enerji dönüşümünde/tasarrufunda peyzaj donatılarının konumlandırılması önemlidir. Aynı zamanda havalandırma, ısınma ve soğutma sistemlerinin sürdürülebilir kılınmasının, geri dönüşüm noktasında çevre kirliliğine karşı önemli bir yeri vardır. Bunula birlikte bina inşaatında da geri dönüşümlü malzemelerin kullanımasına enerji tasarrufunda da bazı araştırmalarda vurgu yapılmıştır. Planlama ve yönetim, araziye mevzuat kullanarak çevre koruma ve kullanım kontrolünü sağlar (Cetin ve ark., 2010; Cetin, 2013; Cetin, 2015a,b,c,d; Cetin 2016a,b,c; Cetin ve Sevik, 2016a,b,c; Cetin ve ark., 2017; Kaya ve Yücedağ, 2017; Yücedağ ve ark., 2017; Yücedağ ve Kaya, 2017a,b; Kaya ve ark., 2018a,b; Cetin ve ark., 2018a,b,c; Yücedağ ve ark., 2018; Kaya ve ark., 2019; Yücedağ ve ark., 2019; Cetin ve ark., 2019; Cetin, 2019). Büyükşehirler hayatın zor olduğu, yönetimlerin yatırımlarla bu durumu kolaylaştırmaya çalıştığı şehirlerdir. Ancak butik kentler, ulaşımın yaya ve bisikletli olarak sağlandığı, bireylerin yaya olarak faaliyetlerde bulunduğu karışık olmayan daha sade şehirlerdir. Dolayısıyla kentsel refahın artmasında da etkili rolü önemsenecek düzeydedir (Topal ve ark., 2016). Çanakkale kent yapısı itibariyle; kanal kent, liman kenti, tarih kenti, sosyal kent ve butik kent gibi markalaşma potansiyellerine sahip, stratejik kentlerden biridir. Kent genelinde bisikletli ve yaya ulaşım mesafesinde olma fırsatına sahip Çanakkale kent dokusu sosyal, kültürel ve coğrafi yapısı ile de butik şehir havasında olmasıyla da öne çıktığı görülmektedir. Bu kapsamda çalışmanın yürütüldüğü alanlarda; başta Fevzipaşa ve Kemalpaşa mahalleleri olmak üzere eski kordon boyunca dış mekan ağırlıklı yapılan incelemelerle bu yerleşimlerde sokak ve caddelerin insan ilişkileri temelinde kişileri biraya getiren dış mekan tasarımlarının olduğu tespit edilmiştir. Ancak ne var ki, mevcut yapıya karşın hali hazırda bazı sokaklarda araç trafiğine izin verilmesi noktasında sıkıntıların yaşanması da göze çarpmaktadır. Buna ilaveten eski kordon için de benzer bir durumdan bahsedilebilir. Zira Kayserili Ahmetpaşa caddesinin de araç trafiğine açık olması özellikle Çanakkale iskelesinin kaçınılmaz kıldığı hafif ve ağır tonajlı araç trafiği de bu anlamda olayın ciddiyetini ortaya koyma noktasında 
oldukça önemlidir. Bu açılardan bakıldığında Çanakkale'nin pratik kent olgusunu değiştirme ve geliştirmeye yönelik acil çözüm odaklı planlama stratejilerine intiyaç olduğu gerçeği aşikardır. Bu çalışmada da sözü edilen ve üzerinde durulması önemle gereken hususlar kapsamında çözüm önerileri geliştirilmeye çalışılmıştır. Ayrıca bu yolla kent insanının daha sosyal iletişime ilişkileri geliştirmeye odaklı peyzaj düzenlemelerine, yapısal değişimlere ve bu anlamda yerel yönetimlerin sorumluluklarına dikkat çekilmeye çalışılmıştır (Yavuzçehre ve Donat, 2017). Çanakkale'de pratik kentin mevcut durumuna çözüm odaklı yaklaşımlara aşağıdaki sorulara cevaplar aranarak ulaşılmaya çalışılmıştır.

- İskele donatısının kent dışında planlanması kentin pratik yapısına katkı sağlar mı?

- Araç trafiği bakımından kent içindeki yoğunluğun azalması kentin peyzaj dokusunu değiştirme ve geliştirme noktasında etkili olur mu?

- Araç park imkanlarının katı/ısansörlü otopark gibi yeni tasarımlarla desteklenmesi kent içi araç trafiğinin azalmasında sosyal ilişkiler açısından fonksiyonel bir etki yapar mı?

Söz konusu hipotezler üzerine yoğunlaşan bu çalışmadan elde edilebilecek veriler kapsamında Çanakkale kentsel ve sosyal yapısının pratik kent olgusuna katkısı araştırılmıştır. Sonuç olarak, öneriler doğrultusunda yer verilecek planlamalarla Çanakkale kentsel yapısında değişim ve gelişmelere bağlı olarak kentin "Butik Kent" olgusunun markalaşması adına olumlu mesafe kat etmesi planlanmaktadır.

\section{MATERYAL VE YÖNTEM}

Çalışma Çanakkale lokalizasyonunda gerçekleşmiş olup, coğrafi konumu itibariyle $40^{\circ} 8^{\prime} 38.31 "$ Kuzey Enlemi ve $26^{\circ} 24^{\prime} 4.86 "$ Doğu Boylamı ile $40^{\circ} 8^{\prime} 58.50 "$ Kuzey Enlemi ve $26^{\circ} 24^{\prime} 7.34^{\prime \prime}$ Doğu Boylamının kesiştiği koordinatlar arasında yer alan Fevzipaşa ve Kemalpaşa Mahallesi ile Canakkale İskele Meydanı/Eski Kordon kapsamında yürütülmüştür. Yaklaşık verildiği sırayla 314 da, 72 da ve 20 da'lık alan ölçüsüne sahip olan çalışma alanının kıyı bandı (Eski Kordon) uzunluğu yine yaklaşık 1 km'ye karşılık gelmektedir (Şekil 1). Gezi, gözlem ve inceleme odaklı alan çalışması yapılarak alanın görselleri ile peyzaj olanak ve donatıları kapsamında verilere ulaşılmıştır. Söz konusu veriler doğrultusunda mevcut durumun ortaya konduğu bu çalışmada alanda değişim ve gelişime yönelik butik kent olgusunda katkılara yer verilmiştir. Bu kapsamda çalışma 3 yönlü yürütülmüştür. Bunlar:

- Çalışma alanı özellikle Fevzipaşa ve Kemalpaşa Mahalleleri kapsamında mevcut durumun ortaya konması,

- İskele donatısı ve Eski Kordon bağlamında değişim ve gelişmelerin belirlenmesi, 3. Alanda araç trafiğine pratik kent olgusunda çözüm önerilerinin geliştirilmesi şeklinde üç önemli strateji olarak öne çıkmaktadır.

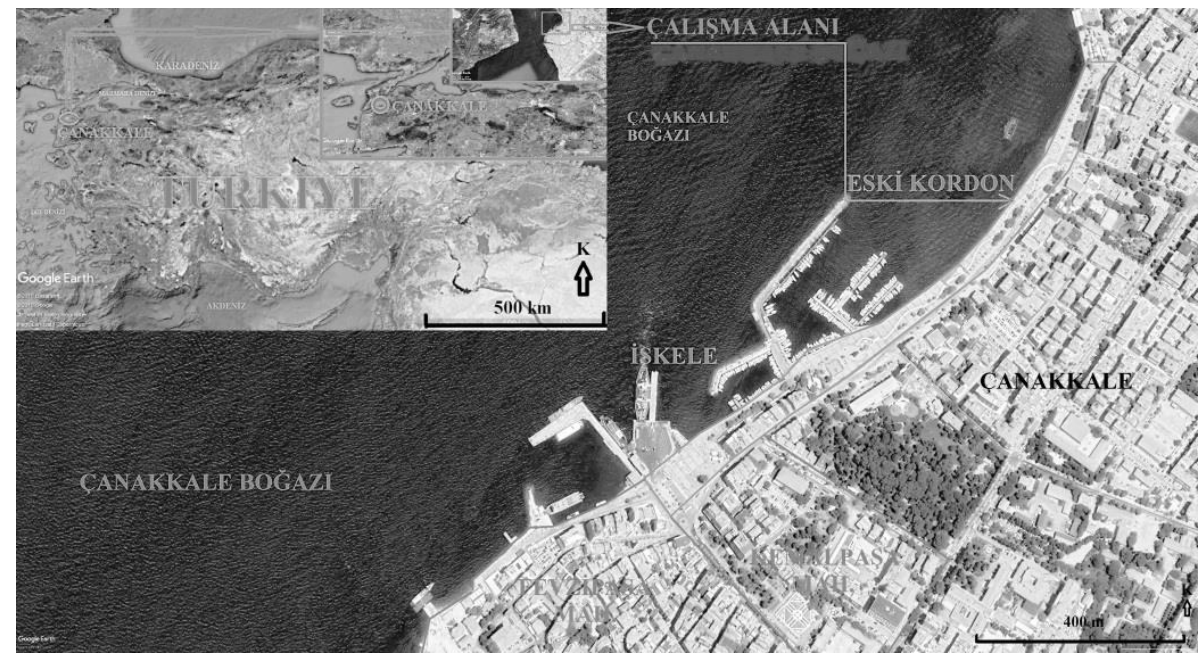

Şekil 1. Çalışma alanı kapsamında değerlendirilen Fevzipaşa ve Kemalpaşa Mahalleleri ile Eski Kordon'un Çanakkale ilindeki coğrafi konumları (Google Earth, 2019'den değiştirilerek) 


\section{BULGULAR}

Çalışma bulgularına üç önemli aşamada ulaşıımıştır.

- Çalışma alanı kapsamında mevcut durumun ortaya konması,

- İskele donatısı ve Eski Kordon bağlamında değişim ve gelişmelerin belirlenmesi, İskele donatısının kent dışında tasarlanması, Eski kordonun yeni peyzaj olanak ve donatıları kapsamında desteklenmesi ve bitkilendirme tasarımı ile rekreasyonel kullanım potansiyelinin artırılması,

- Çalışma alanında araç trafiğine pratik kent olgusunda çözüm önerilerinin getirilmesi. Katı/asansörlü otopark tasarımlarıyla kent içi trafik problemine çözüm getirmekle Çanakkale'nin Butik Kent niteliğinin geliştirilmesinin sağlanması şeklindeki başlıklarda çalışmanın yoğunlaştığından bahsedilebilir.

1. İskele meydanının mevcut yapısına göre araç trafiğine açık olması başta Çanakkale'nin sosyal ilişkiler açısından olmak üzere kentsel yaşamı fiziki açıdan da zorlayan etkisinin öne çıktığını görmekteyiz. Bitkilendirme tasarımının meydan ölçeğinde yetersizliği de göze çapmaktadır. İskele dokusunun kent dışı tasarımında yoğunlaşacak bir çalışma nispeten kent içi araç trafiğinde rahatlama sağlayabilecektir (Şekil 2). Hatta bu yerlerin araç trafiğine kapanması durumunda Çanakkale'nin pratik kent dokusuna sosyal ve fiziki boyut kapsamında pozitif katkı da sağlamış olacaktır (Şekil 2). Kent kıyı bandının (Eski kordon), sosyal aktivite bakımından değerlendirildiğinde kişilerin pasif rekreasyonel eğilimlerini mümkün kılan balıkçı iskelesi, oturma birimleri, iklimin olumsuz etkilerini azaltacak bitkilendirme, seyir terası, gözlem cepleri, pergola, resim ve fotoğrafçılık gibi sanatların ön plana çıktığı vista noktaları; yaşamı kolaylaştıran donatılar grubundan aydınlatma birimleri, çöp kovaları, dijital bilgilendirme/tanıtım/reklam panoları, sınır elemanları, bisiklet park yerleri, taşınabilir büfeler; aktif rekreasyonel eğilimleri mümkün kılan özellikle gençler için elektronik/mekanik kay kay pistleri, çocuklar için mini çocuk oyun alanları, çok amaçlı platformlar gibi yetersizlikler tespit edilen donatılar arasında yer almaktadır (Şekil 2).

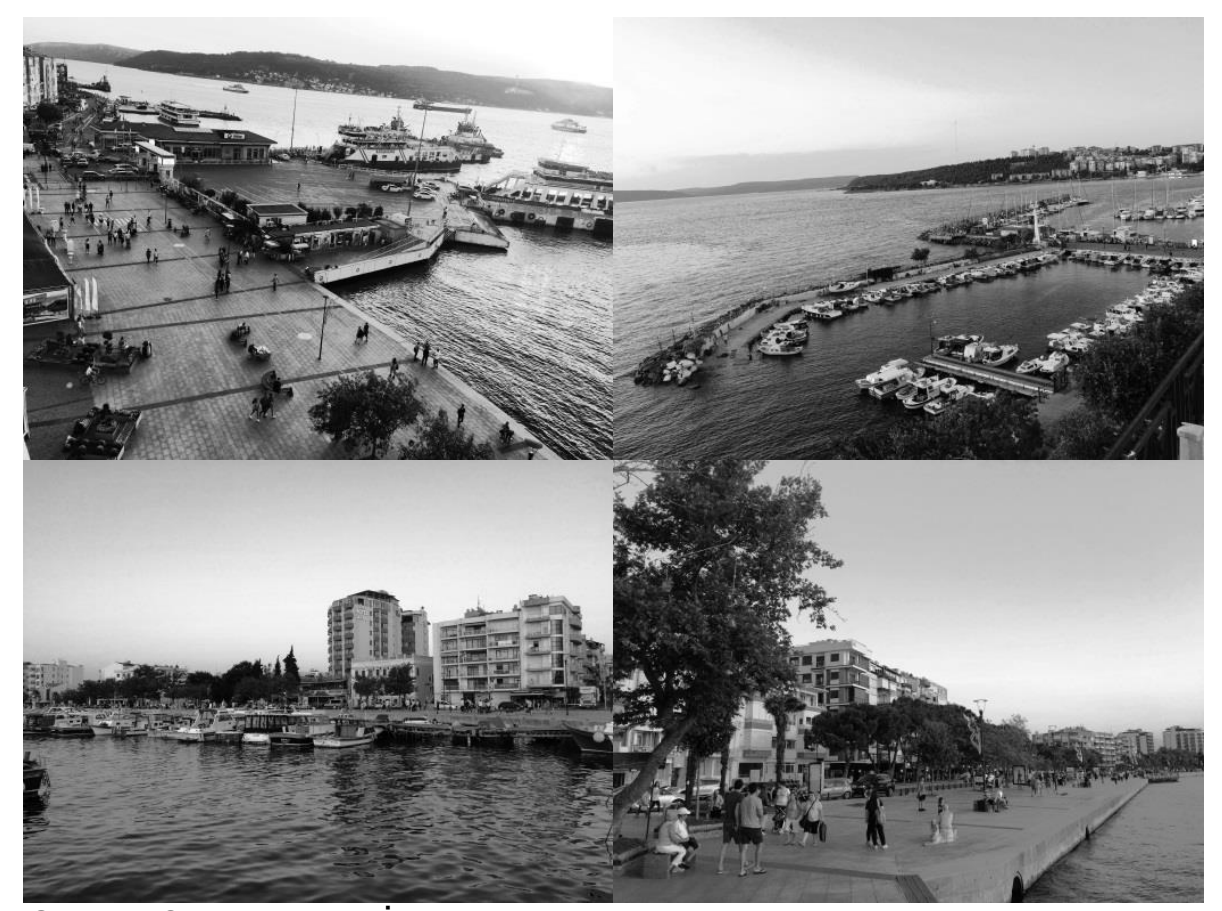

Şekil 2. Saat yönünde İskele Meydanı, Yat Limanı ve Eski Kordon görselleri 
Fevzipaşa (yaklaşık 314 da) ve Kemalpaşa Mahallesi'nde (yaklaşık 72 da) (Google Earth, 2019' den hesaplanarak) yer alan sokak donatılarının ağırlıklı olarak farklı tasarımları, araç trafiğinden uzak olması, sosyal, dini, ekonomik yaşam tarzı olarak da diğer sokak ve caddelere göre farklılık arz etmesi söz konusu iki mahallenin diğer Çanakkele merkez mahalleleriinden bariz bir şekilde ayrılmasında etkili olmaktadır. Söz konusu mahallaler kapsamındaki Esenler, Cevatpaşa, İnönü, Namık Kemal ve Barbaros Mahallaleri'nde de benzer yapıda sokaklar bulunmaktadır (Şekil 3-4).

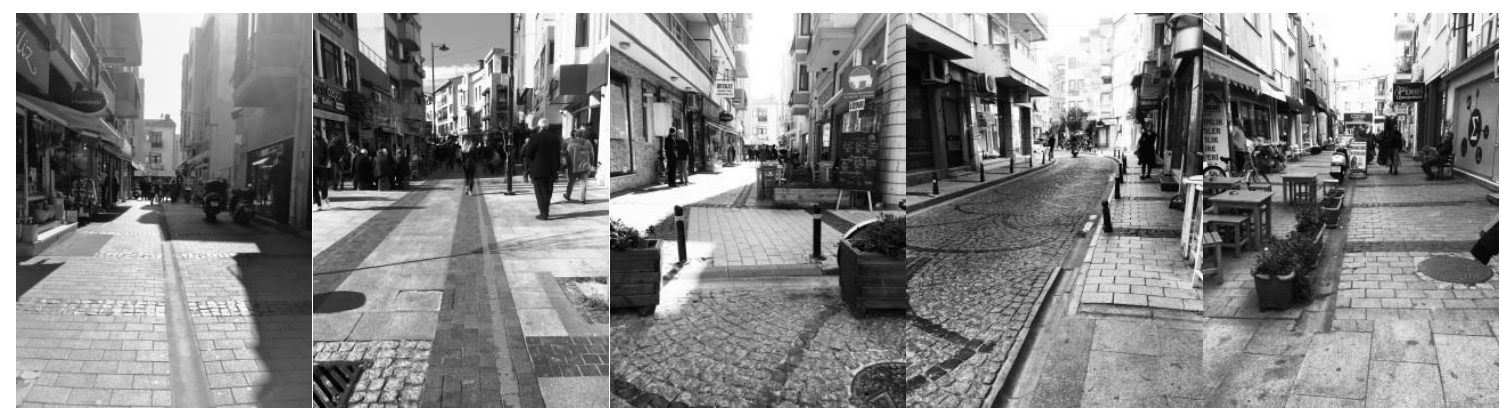

Şekil 3. Kemalpaşa Mahallesi'nde bulunan bazı sokaklardan görseller

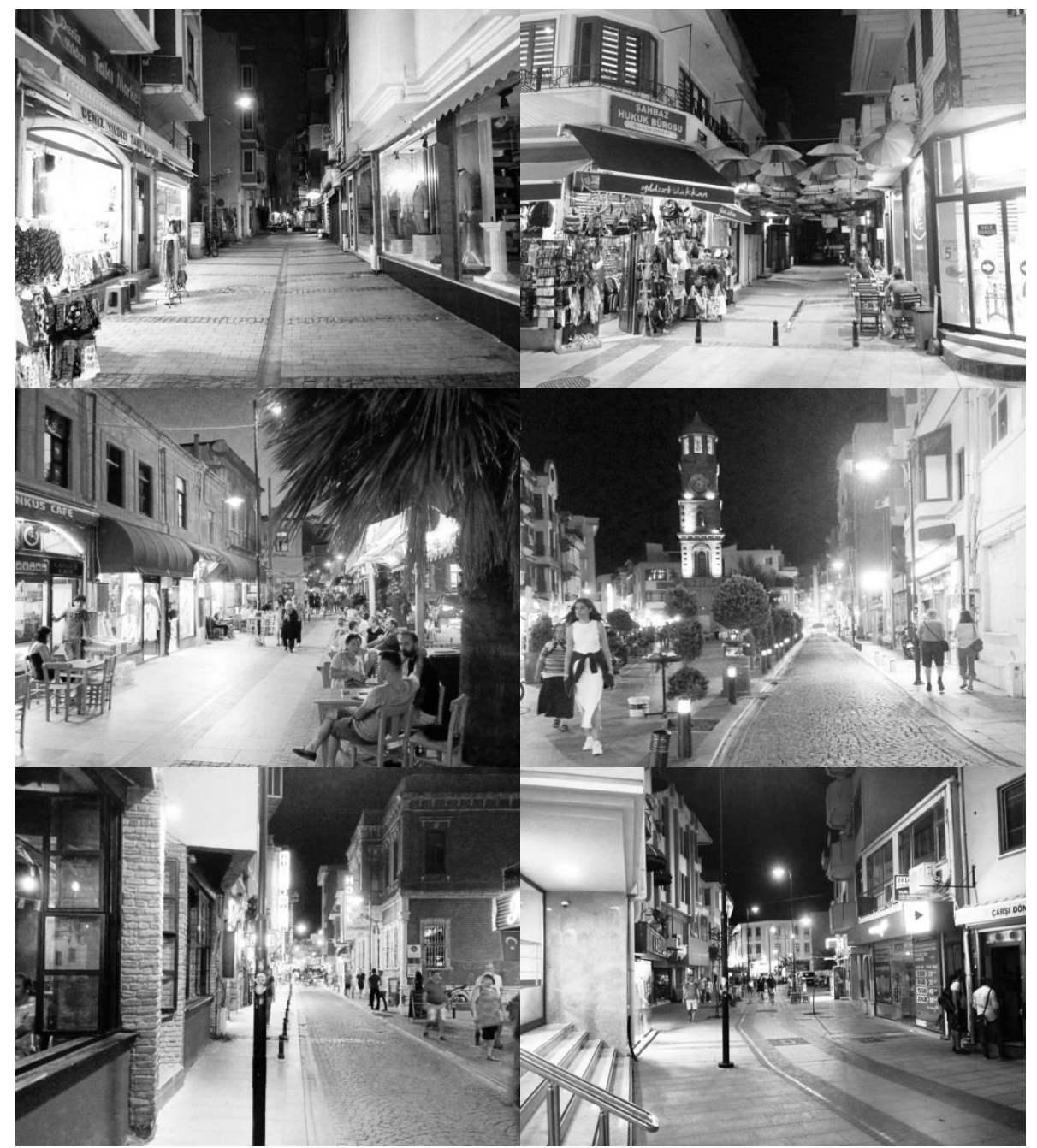

Şekil 4. Fevzipaşa Mahallesi'nde bulunan bazı sokaklardan görseller 
2. Tasarımda söz konusu peyzaj yapısallarına yer verilmesi kent kıyı bandının (eski kordon) yenilikçi ve rasyonel yaklaşımlarla kentli için daha kullanışlı duruma getirilmesinin önü açılmış olacaktır. Bitkilendirmeye odaklı planlamaların kordon boyu peyzajına sağlayacağı getiriler açısından kullanılan süs bitkisi grubundan özellikle ağaç ve ağaççık türünden bitkilerle estetik ve fonksiyonel amaçlı olmasını gerekli kılmaktadır. Bölge ekolojisinin hakim olduğu nem, rüzgar ve güneşin etkisini en aza indirebilecek, sık dokulu geniş taç yapan, herdem yeşil türlerin tercihi bu anlamda önem arz etmektedir. Ağaç ve ağaççık grubundan bitki türlerini; Platanus orientalis/Doğu çınarı, Pinus pinea/fıstık çamı, Betula pendula/Huş ağacı, Acer negundol Akçaağaç, Lagerstroemia indica/Oya ağacı, Ficus indica/İskenderun kauçuğu, Ginkgo bloba/Mabet ağacı, Aesculus hippocastanum/At kestanesi, Tilia tomentosa/Ihlamur ağacı şeklinde sıralamak mümkündür.
Eski Kordon boyuna paralel uzanan Kayserili Ahmetpaşa Caddesi 4-5 m'lik genişliğe sahiptir. Gidiş-geliş yönünde iki taraflı sirkülasyona sahip yol, alanda hareket kabiliyetini sınırlayan önemli bir durum arz etmektedir. Dolayısıyla bu durum spesifik açıdan kentin pratik yaşam ritüeline ters düşmektedir. Söz konusu kuzey-güney yönünde uzanan yaklaşık $1 \mathrm{~km}$ uzunluğundaki sahil yolunun araç trafiğine kapatılması, yaklaşık 20 da' lık alana sahip bu aksın peyzaj planlaması kapsamında kentlinin rekreasyonel intiyaçlarının karşılanması bakımından yine alternatif bir peyzaj alan kullanım türü olarak alana kazandırıması sağlanmış olacaktır. Bu kazanım Çanakkale açısından pratik kent olgusuna da katkı sağlamış olabilecektir. Söz konusu alanın da aynı tasarı ve planlama stratejileriyle ele alınması sosyal ve fiziki anlamda kantin dokusunda yer alabileceği tartışılmazdır (Şekil $5)$.

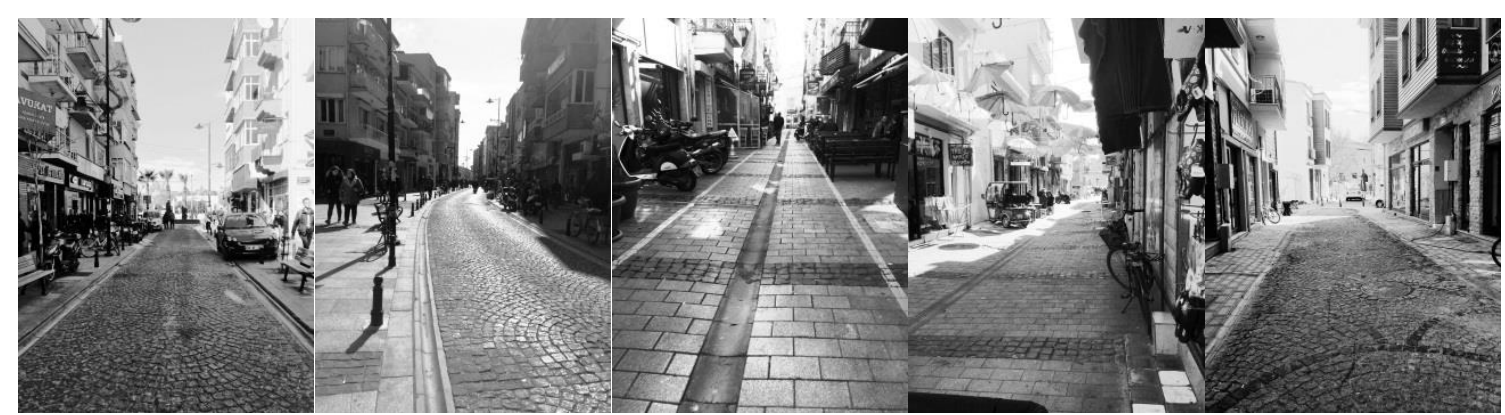

Şekil 5. Fevzipaşa ve Kemalpaşa Mahallesi'nde araç trafiğine açık bazı sokaklardan görünümler

3. Kent içi bazı sokaklarda araç trafiğinin devam etmesi mevcut yapıyı sosyal ilişkiler açısından olumsuz etkilemektedir (Şekil 3). Özellikle araç trafiğinin geldiği boyutta kent içi sosyal yaşamın özellikle yaz mevsiminde içinden çıkılmaz düzeylere geldiği aşikardır. Araç ve yaya trafiğinde önceliğin toplu taşıma araçlarına verilmesinin yanında özellikle yaya trafiğinin ele alınması gerekliliği vardır. Ayrıca, yürüme mesafesinde tesis edilecek otopark sistemlerinin aralarında entegreli olması da planlama dahilinde tutulması gerekli uygulamalardandır. Sıkışık, iç içe girmiş, dar sokak yapısına sahip Çanakkale kent merkezinden 1520 dakikalık yürüme mesafesinde uzaklıklar temel alınarak tesis edilecek yeryüzü altı veya üstü yönelimli katlı ya da asansörlü otopark yapıları (ringopark, skypark, layerpark, optilift park gibi) kent içi bu sarmal ve içinden çıkılmaz durumu nispeten çözüm odaklı bir zemine taşıyabilecektir (URL-1, 2019)(Şekil 6). 


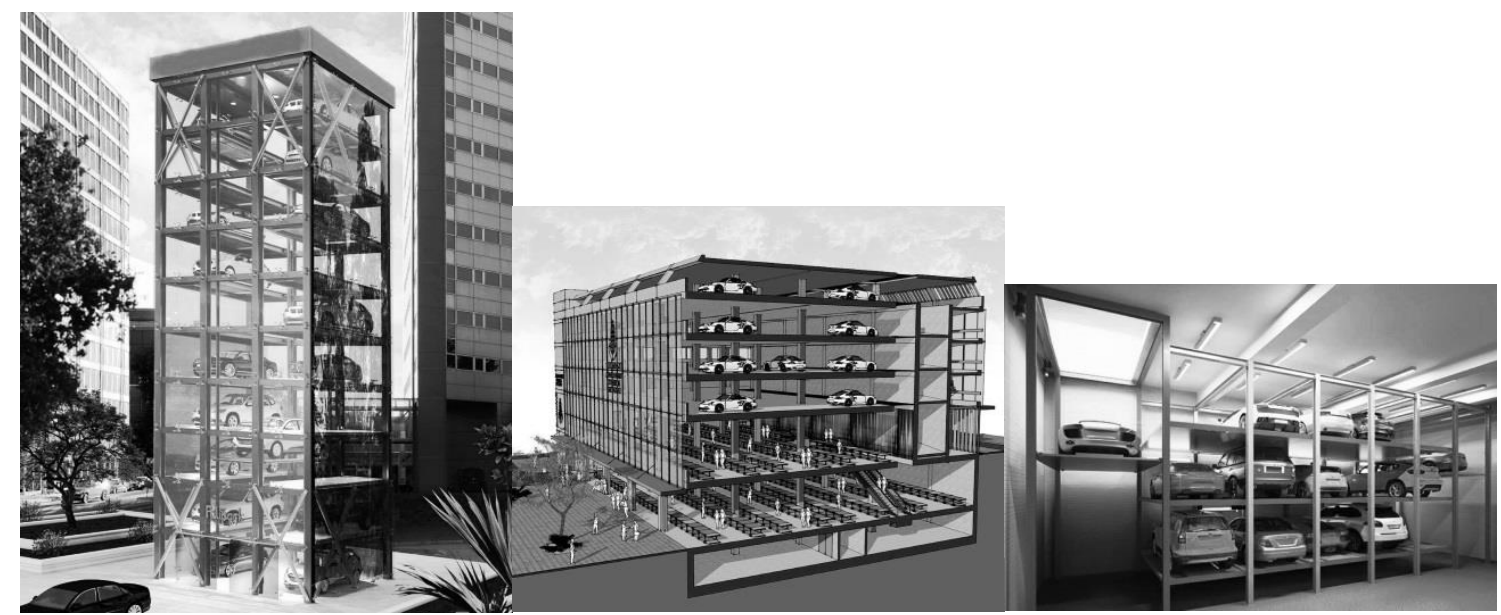

Şekil 6. Katı ve asansörlü otopark sistemlerine model olabilecek görseller (URL-1, 2019)

Çanakkale'de kent merkez yapısının araç trafiğinden uzak planlanması butik kent olması yolunda oldukça fazla mesafe kat etmesi anlamına gelmektedir. Bu anlamda kentin orta ve uzun vadede otopark planlanması ölçütlerini bu temeller üzerine kurgulamak gereği unutulmamalıdır. Bu sayede Çanakkale'nin ağırlıklı özgün yapısı noktasında baskın karakterlerin su yüzene çıkması sağlanarak geleceğe emin adımlarla ilerlemesinin önü açılmış olabilecektir. Haldenbilen ve ark. (1999) da çaıışmalarında benzer sonuçlara ulaşmışlardır. Çanakkale'de kent içindeki yol içi park sistemi özellikle kısa süreli olmak üzere planlanmıştır. Saatlik ücret karşılığında otopark işletimi yerel yönetimce sağlanmaktadır. Kent içi özellikle kısa süreli parklarda park ücretlerinin yüksek tutulması nispeten caydırıcı etkisi sayesinde kent içi trafiğin çözümünde etkili olabilmektedir. Yol dışı otopark planlamaları henüz yeterli düzeyde bulunmamaktadır. Bu çalışmada yol içi park ücretlerinin yüksek tutulması ve yol dışı araç park yerleri inşa edilerek araç trafiğinin kent içinde ki potansiyelinin azaltılması yönünde rasyonel bir adım atılabileceğine vurgu yapılmaktadır.

\section{TARTIŞMA VE SONUÇLAR}

Çanakkale tarihi süreçte kıyı bandı önceliğinde yerleşim potansiyeline sahip olmuş, sonraları diğer kıyı/sahil kentlerinde olduğu gibi kıyı boyunca ve içeriye doğru gelişme göstererek bugünkü şeklini almıştır. Günümüz kentlerinin ortak yaşam alanları, aidiyetleri, yerellikleri, kent insanının kültürel etkileşimlerini pratik hale getirmesi ve sosyal bellek aracılığıyla evrilmesi ile nesilden nesile aktarılmasını kaçınılmaz kılmaktadır (Yazar, 2015). Eski kent yapısından kalma özellikle Fevzipaşa ve Kemalpaşa Mahallesi ile diğer mahallelerdeki bazı kesimler de sokak ve cadde potansiyelleri ile dar, özgün tasarım, peyzaj donatıları gibi bileşenler kapsamında ayrıcalıklı bir yapı arz etmektedirler. Bu durum Çanakkale' nin sosyal kent; bir başka deyişle "Butik Kent" olma nok- tasında öne çıkmasını sağlamıştır. Bu çalışmada Çanakkale'nin bu yönü mercek altına alınmaya çalışılmıştır. Çalışmadan elde edilen sonuçlar kapsamında aşağıda literatür karşılaştırmaları yer almaktadır. Cereci (2010) çalışmasında artan nüfusa bağlı olarak genişleyen kentlerin planlama zorluklarına da bu çalışmada olduğu gibi vurgu yapmıştır. Ayrıca yine bu çalışmayla örtüşür biçimde Cereci (2010) çalışmasında söz konusu planlamaların sosyal ilişkiler önceliğinde yani bir araya gelerek insanların eğlenme, dinlenme, düğün, dernek, taziye gibi çok amaçlı buluşabilecekleri ortamlar olarak planlanması gerekliliğine değinmiştir. Yavuzçehre ve Donat (2017) çalışmasında sakin kentlerde kamusal alan planlamalarının tesisinde ve geliştirilmesinde çoklu aktörlerin yanı sıra kent sakinlerinin iradelerinin de payı olması gerektiğinden bahsetmektedir. Bu çerçevede planlamaların kültürlerin harmanlanması amacına dönük kullanılması gereken araç niteliğine bürünmesi de vurgulanmıştır. Topal ve ark., (2016) kentsel alan planlamalarında yapısal tasarımlarda bu çalışmada olduğu gibi ekolojik faktörlerin öncelikli olarak ele alınması gerekliliğine vurgu yapmışlardır. Bu çalışmada da olduğu gibi "vista noktalarına" çalışmalarında yer vermişlerdir. Ayrıca öncelikli yaya yolları ve alanları olmak üzere toplu taşıma araçlarının da bu çalışmada olduğu gibi kent içinde yaygınlaştırılması tasarısına yer verilmiştir. Türk ve Seydioğulları (2018), Alanya iskele/rıhtım bölgesi için yaptıkları mekânsal analiz çalışmasında elde ettikleri bölgenin çevre bileşenleriyle bir bütünlük arz etmediği bulgusu bu çalışmayla da örtüşür bir benzerlik göstermesi bakımından önemli bulunmuştur. Ayrıca, Yücedağ ve ark., (2018) çalışmasında Denizli'nin Çivril ilçesinde yer alan açık ve yeşil alanlar, parklar gibi toplumun rekreasyonel eğilimlerini gerçekleştirdikleri alanlarda bitkilendirme kapsamında ağaç formunda odunsu bitki türlerine yer verilmesinin söz konusu eğilimlerin daha rasyonel değerlendirilmesine imkan tanıdığı sonucuna ulaşmışlardır. Bu çalışmada da Çanakkale iskele meydanı, 
eski kordon boyu gibi kent dokusunda önemli yerlere sahip bölgelerde yüksek boylu ağaçların yer aldığı bitkilendirme tasarımıyla alana kazandırımasının sosyal ilişkiler, rekreasyonel aktiviteler açısında katkı sağlayacağına vurgu yapılmıştır. Sarıçay kanalına ve kıyıya paralel gelişen tekstürü, sosyal yönü ve mimari formları ile öne çıkmış Çanakkale kenti, "Butik Kent" olmasının yanı sıra "Liman ve Kanal Kenti" olması yolunda da aday kentlerden birisi olarak Unesco tarafından koruma altına alınması (dünya mirası listesi) gereken kentlerden bir tanesidir. Kente özgün söz konusu markalaşmaların nispeten geliştirilmesine yönelik bu çalışmayla öne çıkan önerilere aşağıda yer verilmeye çalışılmıştır.

- Mevcut İskele yapısının kent dışında planlanması,

- Yeraltı ve yerüstü istikametinde çok katlı ve asansörlü otoparkların planlanması,

- Eski kordon lokalizasyonunda peyzaj olanak ve donatılarına değişim ve gelişim adına yeni planlamalarla desteklenmesi,

- Bitkilendirmede nem, rüzgar ve güneşin etkisini azaltan soliter ve grup bitkilendirmelerine yer verilmesi,

- Çöp birimleri, aydınlatma üniteleri, oturma grupları, pergola, bilgilendirme panoları gibi yapılara planlamalarda yer verilmesi,

- Seyir terası, gözlem cepleri, çok fonksiyonlu iskele tasarımları ile kıyı bandının zenginleştirilmesi gibi olanak ve donatıların yer aldığı çalışmalar Çanakkale'nin sosyal kent olgusuna önemli katkılar sağlayabilecektir.

\section{KAYNAKLAR}

Eroğlu, O., Yalçın, A. (2014). Yeni Bir Rekabet Formu Olan Kent Rekabetçiliğine Yönelik Literatür Taraması. Çankırı Karatekin Üniversitesi, İktisadi ve İdari Bilimler Fakültesi Dergisi, 4(1), 19-42.

Cereci, S. (2010). Kent Planlaması Bağlamında Kentsel Alanlarda İletişim Ortamlarının Oluşturulması Sorunu. Akademik Bakış Dergisi, Sayı 22, Ekim - Kasım - Aralık - 2010, Uluslararası Hakemli Sosyal Bilimler E-Dergisi, ISSN:1694-528X İktisat ve Girişimcilik Üniversitesi, Türk Dünyası. Kırgız-Türk Sosyal Bilimler Enstitüsü, CelalabatKirgizistan. http://www.akademikbakis.org.

Cetin, M., Topay, M., Kaya L.G., Yilmaz, B. (2010). Efficiency of bioclimatic comfort in landscape planning process: case of Kutahya, Turkish Journal of Forestry 1 (1), 83-95.

Cetin, M. (2013). Chapter 27: Landscape Engineering, Protecting Soil, and Runoff Storm Water. InTech-Open ScienceOpen Minds. Book: Advances in Landscape ArchitectureEnvironmental Sciences. Eds: Murat Ozyavuz, , ISBN 978953-51-1167-2, pp.697-722.

Cetin, M. (2015a). Determining the bioclimatic comfort in Kastamonu City. Environmental Monitoring and Assessment, 187(10): $\quad 640, \quad \mathrm{http}: / /$ link.springer.com/article/10.1007\%2Fs10661-015-4861-3
Cetin, M. (2015b). Using GIS analysis to assess urban green space in terms of accessibility: case study in Kutahya. International Journal of Sustainable Development \& World Ecology, 2015, 22(5): 420-424, DOI: 10.1080/13504509.2015.1061066. http://dx.doi.org/10.1080/13504509.2015.1061066

Cetin, M. (2015c). Evaluation of the sustainable tourism potential of a protected area for landscape planning: a case study of the ancient city of Pompeipolis in Kastamonu. International Journal of Sustainable Development \& World Ecology, 22(6), 490-495

Cetin, M. (2015d). Chapter 55: Using Recycling Materials for Sustainable Landscape Planning. ST. Kliment Ohridski University Press, SOFIA. Book: Environment and Ecology at the Beginning of 21st Century. Eds: Recep Efe, Carmen Bizzarri, İsa Cürebal, Gulnara N. Nyusupova, ISBN:978954-07-3999-1, pp.783-788.

Cetin, M. (2016a). A Change in the Amount of $\mathrm{CO}_{2}$ at the Center of the Examination Halls: Case Study of Turkey. Studies on Ethno-Medicine, 10(2), 146-155

Cetin, M. (2016b). Determination of bioclimatic comfort areas in landscape planning: A case study of Cide Coastline, Turkish Journal of Agriculture-Food Science and Technology 4 (9), 800-804

Cetin, M. (2016c). Sustainability of urban coastal area management: a case study on Cide, Journal of Sustainable Forestry, 2016, $35 \quad$ (7), 527-541, http://dx.doi.org/10.1080/10549811.2016.1228072

Cetin, M., Sevik, H. (2016a) Evaluating the recreation potential of Ilgaz Mountain National Park in Turkey. Environmental Monitoring and Assessment, 188(1):52, http://link.springer.com/article/10.1007/s10661-015-5064-7

Cetin, M., Sevik, H. (2016b). Assessing Potential Areas of Ecotourism through a Case Study in Ilgaz Mountain National Park, InTech, Chapter 5, Eds:Leszek Butowski, 190, ISBN:978-953-51-2281-4, 81-110, http://www.intechopen.com/books/tourism-from-empirical-research-towardspractical-application/assessing-potential-areas-of-ecotourism-through-a-case-study-in-ilgaz-mountain-national-park

Cetin, M., Sevik, H. (2016c) Change of air quality in Kastamonu city in terms of particulate matter and $\mathrm{CO} 2$ amount. Oxidation Communications 39, No 4-II, 3394-3401.

Cetin, M., Mossi, M.M.M., Akbudak, K.Y. (2017). Chapter 35: Visual Examination of Natural and Cultural Landscape Values in Kastamonu City Center for Sustainable Spatial Development. Ecology, Planning and Design. Eds: Irina Koleva, Ulku Duman Yuksel, Lahcen Benaabidate, St. Kliment Ohridski University Press, ISBN: 978-954-07-4270-0, pp. 465-477.

Cetin, M., Adiguzel, F., Kaya, O., Sahap, A. (2018a) Mapping of bioclimatic comfort for potential planning using GIS in Aydin. Environment, Development and Sustainability, 20 (1): 361-375.https://doi.org/10.1007/s10668-016-9885-5

Cetin, M., Sevik, H., Canturk, U., Cakir, C. (2018b) Evaluation of the recreational potential of Kutahya Urban Forest. Fresenius Environmental Bulletin, 27(5):2629-2634.

Cetin, M., Zeren, I., Sevik, H., Cakir, C., Akpinar, H. (2018c). A study on the determination of the natural park's sustainable tourism potential. Environmental Monitoring and Assessment. 190(3): 167.https://doi.org/10.1007/s10661018-6534-5 
Cetin, M. (2019). The effect of urban planning on urban formations determining bioclimatic comfort area's effect using satellitia imagines on air quality: a case study of Bursa city. Air Quality, Atmosphere \& Health. (Air Qual Atmos Health) (2019): 1-13. https://doi.org/10.1007/s11869-019-00742-4 https://link.springer.com/article/10.1007\%2Fs11869-01900742-4

Cetin, M., Adiguzel, F., Gungor, S., Kaya, E., Sancar, M.S. (2019). Evaluation of thermal climatic region areas in terms of building density in urban management and planning for Burdur, Turkey. Air Quality Atmosphere \& Health (Air Qual Atmos Health) $12 \quad$ (9): 1103-1112. https://doi.org/10.1007/s11869-019-00727-3; https://link.springer.com/content/pdf/10.1007\%2Fs11869019-00727-3.pdf

Haldenbilen, S., Murat, Y.Ş., Baykan, N., Meriç, N. (1999). Kentlerde Otopark Sorunu: Denizli Örneği, Pamukkale Üniversitesi Mühendislik Fakültesi Mühendislik Bilimleri Dergisi, Yıl Cilt Sayı Sayfa: 1999: 5: 2-3: 1099-1108.

Kaya, E., Agca, M., Adiguzel, F., Cetin, M. (2019). Spatial data analysis with $\mathrm{R}$ programming for environment. Human and Ecological Risk Assessment: An International Journal 25 (6): https://doi.org/10.1080/10807039.2018.1470896 https://www.tandfonline.com/doi/full/10.1080/10807039.2018.1470896

Kaya, L.G., Yücedağ, C., (2017). Determination of the Outdoor Recreational Potential in Burdur City, Turkey. Chapter 19 (Editors: Recep Efe, Murat Zencirkıran, Jan A. Wendt, Zeynal Tümsavaş, Halil Unal, Bilyana Borisova, Current Trends in Science and Landscape Management), St. Kliment Ohridski University Press, ISBN:978-954-07-4338-7, p. 217-228, Sofya.

Kaya, L. G., Kaynakci-Elinc, Z., Yücedağ, C., Cetin, M. (2018a). Environmental outdoor plant preferences: a practical approach for choosing outdoor plants in urban or suburban residential areas in Antalya, Turkey. Fresenius Environmental Bulletin, 27(12), 7945-7952.

Kaya, L.G., Yücedağ, C., Aşıkkutlu, H.S., Çokyiğit, H., (2018b). Spatial Design Approaches to Prevent Damages from Earthquake inside the Buildings. Mehmet Akif Ersoy University, Journal of Applied Science Institute, 9(1): 55-62.

Kurt, N. (2018). Kent Yönetiminde Ekonomik Misyon ve Gelecek Perspektifi. Kent Akademisi/Kent Kültürü ve Yönetimi Hakemli Elektronik Dergi/Cilt:11 Sayı: 2, Yaz 2018 www.kentakademisi.com Urban Academy/Rewieved Journal of Urban Culture and Management/Volume: 11 Issue: 2, Summer 2018.

Pustu, Y. (2006). Antik Siteden Dünya Kentine. Sayıştay Dergisi Sayı: 60. http://www.acarindex.com/dosyalar/makale/acarindex-1423911641.pdf.

Tatlıdil, E. (1992). "Kent Sosyolojisi: Kuram ve Kavramlar", Ege Üniversitesi Sosyoloji Dergisi, Ege Üniversitesi Edebiyat Fakültesi Yayını, Sayı: 3, İzmir, 1992.

Topal, T.Ü. Korkut, A. Kiper, T. (2016). Yerel Kimliğin Kent İle Buluşması: Cittaslow-Yavaş Şehirler. İdil, 2016, Cilt 5, Sayı 25, Volume 5, Issue 25. DOI: 10.7816/idil-05-25-06.
Türk, A. Seydioğullari, H. S. (2018). Kent Kimliğinin Kent Meydanlarına Yansıması: Alanya İskele-Rıhtım Bölgesi Örneği, Mehmet Akif Ersoy Üniversitesi Fen Bilimleri Enstitüsü Dergisi 9(Ek Sayı 1): 205-215 (2018), DOI:10.29048/makufebed.399788

URL-1 (2019). Katlı ve Asansörlü Otopark Sistemleri, http://www.sanpark.eu/sanpark-urunler (Erişim Tarihi: 12.08.2019).

Weber, M. (2003). Şehir, (Çev. Musa Ceylan), Bakış Yayınları, İstanbul, 2003.

Wirth, L. (2002). Bir Yasam Biçimi Olarak Kentlileşme, 20. Yüzyıl Kenti, (Der. ve Çev. Bülent Duru ve Ayten Alkan), İmge Yayınevi, Ankara, 2002.

Yazar, A. (2015). Kent Kültürü ve Kimliğine Tarihsel ve Kuramsal Bakış, Toros Üniversitesi, Sosyal Bilimler Dergisi, ss.117-144, 2015.

Yavuzçehre, P.S. Donat, O. (2017). Türkiye'de Sakin Kent (Cittaslow) Üyeliğinin Kamusal Mekânlara Etkisine Yönelik Bir İnceleme. Pamukkale Üniversitesi, Sosyal Bilimler Enstitüsü Dergisi. ISSN: 1308; E-ISSN: 2147-698. DOİ: 10.5505/pausbed.2017.25901.

Yücedağ, C., Kaya, L.G. (2017a). Attitudes to Protected Areas: A Case of Lake Salda NaturePark in Burdur-Turkey. Chapter 20 (Editors: Recep Efe, Murat Zencirkıran, Jan A. Wendt, Zeynal Tümsavaş, Halil Unal, Bilyana Borisova, Current Trends in Science and Landscape Management), St. Kliment Ohridski University Press, ISBN:978-954-074338-7, p. 229-240, Sofya.

Yücedağ, C., Kaya, L.G. (2017b). Recreational Trend and Demands of People in Isparta-Turkey. Chapter 104 (Editors: Hasan Arapgirlioğlu, Atilla Atik, Robert L. Elliott, Edward Turgeon, Researches on Science and Art in 21st Century), Gece Publishing, ISBN:978-605-180-771-3, p. 927-934, Ankara.

Yücedağ, C., Kaya, L.G., Ulu, A. (2017). Investigation of Landscape Design Efficiency in the Housing Development and the Apartment Complexes of Burdur City, Turkey. Mehmet Akif Ersoy University, Journal of Applied Science Institute, 8(2), 114-122.

Yücedağ, C., Kaya, L. G., Aşikkutlu, H. S., Sağir, E. (2018). Sustaining Urban Forestry Activities: The Case Study of Çivril District, Denizli-Turkey. The Journal of Graduate School of Natural and Applied Sciences of Mehmet Akif Ersoy University 9(Supplementary Issue 1): 216-223, DOI: 10.29048/makufebed.450200.

Yücedağ, C, Kaya, L.G., Cetin, M. (2018) Identifying and assessing environmental awareness of hotel and restaurant employees' attitudes in the Amasra District of Bartin. Environmental Monitoring and Assessment, 190(2): 60. https://doi.org/10.1007/s10661-017-6456-7

Yücedağ, C., Ozel, H. B., Cetin, M., Sevik, H. (2019). Variability in morphological traits of seedlings from five Euonymus japonicus cultivars. Environmental Monitoring and Assessment, 191(5), 285. 